\title{
An Unusual Cause of Secondary Hypertension-Polycythemia Vera -A Rare Case Report
}

\author{
Dr.P.V.Karthik .M.D.(Gen Med), Dr.B.Prabakar.M.D.(Gen Med) \\ Dept.of General Medicine, Chengalpattu Medical College and Hospital, Chengalpattu, Tamil Nadu, India
}

\begin{abstract}
Polycythemia Vera is most common of chronic myeloproliferative disorders [1]. It occurs in about 2 per 100,000 persons, sparing no adult age group. Vertical transmission has been documented, establishing a genetic basis for the disorder. It is more common in males than in females, but females predominate within the reproductive age range. Herein, we describe a $45 \mathrm{yr}$ old patient who presented with accelerated hypertension and pulmonary edema which was found to be secondary to polycythemia vera.
\end{abstract}

Key-words: secondary hypertension, polycythemia vera

\section{Case Report}

A 45 year old male, was admitted with complaints of breathlessness of insidious onset, gradual in progression and of NYHA grade II - III. He also complained of chest discomfort of 1 week duration, dull aching in nature, no radiation of pain and no aggravating or relieving factors.

\section{Examination:}

The patient was diagnosed to be a case of Systemic Hypertension 6 months back but was on irregular treatment. He is also a smoker for past 10 to 15 years smoking 5 to 6 cigarettes / day. On examination patient was conscious, oriented, afebrile, with no pallor, no icterus, no cyanosis, no clubbing, no pedal edema and no generalised lymphadenopathy. He was dyspnoeic. Vital signs showed a pulse rate of 76 / min, regular in rhythm, normal volume, measured in all peripheral pulses, no radio - radio and radio - femoral delay. His Blood pressure was 240 / $\mathbf{1 4 0} \mathbf{~ m m}$ of $\mathbf{~ H g}$ measured in right upper limb in sitting posture, compared in all 4 limbs. His respiratory rate was $33 / \mathrm{min}$, body Temp was $98.5 * \mathrm{f}$ and Spo 2 was $95 \%$. Systemic examination showed normal CVS examination with no murmurs, RS examination showed normal vesicular breath sounds but with bilateral basal fine inspiratory crepitations. Abdominal examination and CNS examination were found to be normal. But Fundus examination showed grade III Hypertensive retinopathy.

\section{Investigation:}

Blood sugar of the patient was $90 \mathrm{mg} \%$, blood urea was $69 \mathrm{mg} / \mathrm{dl}$ and serum creatinine $1.4 \mathrm{mg} / \mathrm{dl}$. Urine routine examination was normal. Chest X-Ray PA view was normal. His CBC on day 1 and 3 were as follows:

\begin{tabular}{|l|l|l|}
\hline & Day 1 & Day 3 \\
\hline TC & $13000 /$ cu.mm & $11700 /$ cu.mm \\
\hline DC & $79 / 12 / 9$ & $85 / 13 / 2$ \\
\hline RBC & $\mathbf{5 . 9 3}$ million/cu.mm & $\mathbf{6 . 5 3}$ million/cu.mm \\
\hline Hb & $\mathbf{2 0 . 7}$ g/dl & $\mathbf{2 2 . 4}$ g/dl \\
\hline PCV & $\mathbf{5 8 . 4} \%$ & $\mathbf{6 2 . 2} \%$ \\
\hline Platelet count & $2.2 \mathrm{lac} /$ cu.mm & 2 lac/cu.mm \\
\hline
\end{tabular}

Peripheral smear study showed erythrocytosis. Bone marrow aspiration showed hypercellularity with predominant erythroid cells. ESR showed increased rouleaux formation. ECG showed normal sinus rhythm and ischaemic changes in leads v3 to v6 and leads I and Avl. ECHO showed concLVH, mild global hypokinesia of LV, LVEF - $44 \%$, mild - mod LV dysfunction, MR (T). USG abdomen showed normal study. Renal artery doppler showed that the main renal artery and intra renal branches on both sides demonstratednormal color flow and waveform pattern. Peak systolic velocity were within normal limits. Serum erythropoietin was $\mathbf{2 . 4 8} \mathbf{~ m I U} / \mathbf{m l}$ (2.6 to 34).

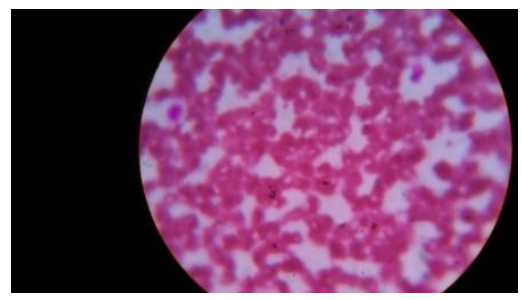




\section{WHO criteria (2009) for Polycythemia vera[7]: \\ Major criteria:}

1. $\mathrm{Hb}>18.5 \mathrm{~g} / 100 \mathrm{ml}$ in men or $16.5 \mathrm{~g} / 100 \mathrm{ml}$ in women or $\mathrm{Hb}>17 \mathrm{~g} / 100 \mathrm{ml}$ in men or $15 \mathrm{~g} / 100 \mathrm{ml}$ in women if associated with $2 \mathrm{~g} / 100 \mathrm{ml}$ increase from baseline that is not attributed to correction of iron deficiency anemia.Hb or Hct $>99$ percentile of reference range for age /sex/altitude or red cell mass $>25 \%$ above mean normal predicted value.

2. Presence of JAK2 V617F or JAK2 exon 12 mutation

\section{Minor criteria:}

1. BM biopsy hypercellular for age with panmyelosis with prominent erythroid, granulocytic and megakaryocytic proliferation.

2. Serum EPO level below the reference range for normal.

3. Endogenous erythroid colony formation in vitro.

For diagnosis of polycythemia vera requires presence of both major criteria or one minor criteria or the presence of first major criteria and two minor criteria. Here the patient satisfied WHO criteria for PCV. The major criteria found in this patient were increased hemoglobin concentration and the two minor criteria present were low serum EPO levels and hypercellular bone marrow.

\section{Diagnosis And Treatment:}

He was diagnosed to be a case of POLYCYTHEMIA VERA / SECONDARY ACCELERATED HYPERTENSION / ACUTE PULMONARY EDEMA. He was treated for the same with Nasal O2, Injlasix $80 \mathrm{mg}$ stat followed by 40 - 40 - 20 , Inj NTG 1 amp in $500 \mathrm{ml} \mathrm{NS} @ 6 \mathrm{~d} / \mathrm{min}$, tab amlodipine 2.5mg 2BD, tab enalapril $2.5 \mathrm{mg} 2 \mathrm{BD}$, tab atenolol 50mg 1OD . He underwent phlebotomy initially at once a week for 3 weeks (around $400-500 \mathrm{ml}$ of blood during each session) and then was planned to continue so every month based on his blood pressure and other symptoms. After 3 months patient's condition gradually improved and his haemoglobin came down to $14.5 \mathrm{mg} / \mathrm{dl}$.

\section{Discussion}

- According to JNC - 8 criteria, the cut off to diagnose a case of hypertension is as follows :

$<60 \mathrm{yrs}->140 / 90 \mathrm{~mm}$ of $\mathrm{Hg}$

$>60 \mathrm{yrs}->150 / 90 \mathrm{~mm}$ of $\mathrm{Hg}$

\section{- Causes of hypertension are -}

1. Primary or essential hypertension

2. Secondary hypertension - Renal parenchymal, renovascular, adrenal, aortic coarctation, obstructive sleep apnea, neurogenic, endocrine, haematologic, monogenic causes etc ..

\section{- Polycythemia -}

It is an increase in circulating red bloodcellsabove normal due to decrease in plasma volume (spurious or relative). There is elevated haemoglobin of $>17 \mathrm{~g} / \mathrm{dLfor}$ men and $>15 \mathrm{~g} / \mathrm{dL}$ for women. Hematocrit is $>60 \%$ in men and $>55 \%$ in women.

Etiology is unknown. Pcv cells have mutation in tyrosine kinase (JK 2) [2]which acts in signaling pathways of EPO receptor, rendering those cells hypersensitive to EPO. Trisomy 8 or 9 is also common. Impaired posttranslational processing of the thrombopoietin receptor, $\mathrm{Mpl}$ is also considered[5]. Polycythemia vera leukocytes also overexpress mRNA for $P R V-1$.

Clinicallythe patients may havemassive splenomegaly, aquagenic pruritus, vertigo, tinnitus, headache, and visual disturbances, Systolic hypertension, venous or arterial thrombosis, Intraabdominal venous thrombosis and on physical examination, a ruddy complexion.

Complications that may arise include sudden massive increase in spleen size associated with splenic infarction or progressive cachexia, myelofibrosis and myeloid metaplasia, acute nonlymphocytic leukemia, acute leukemia, erythromyalgia, intravascular thrombosis of liver, heart, brain, or lungs[8]. The median survival of untreated patients is reported to be 18 months[6]

The drugs currently being used in cases refractory to phlebotomy are IFN-alpha, hydroxyurea, anagrelide and Lestaurtinib[4].

Even though PV is more common in elderly, any patient irrespective of age when presents with symptoms and signs of increased viscosity of blood should be evaluated for myeloproliferative disorders so that early diagnosis and treatment can be initiated for better prognosis. 


\section{References}

[1]. Alchalby $\mathrm{H}$ et al: Impact of JAK2V617F mutation status, allele burden, and clearance after allogeneic stem cell transplantation for myelofibrosis. Blood 116:3572, 2010[PMID: 20489052]

[2]. Cassinat B et al: Classification of myeloproliferative disorders in the JAK2 era: Is there a role for red cell mass? Leukemia 22:452, 2002

[3]. Jones AV et al: JAK2 haplotype is a major risk factor for the development of myeloproliferative neoplasms. Nat Genet 41:446, 2009[PMID: 19363185

[4]. Kiladjian JJ et al: Pegylated interferon-alfa-2a induces complete hematologic and molecular responses with low toxicity in polycythemia vera. Blood 112:3065, 2008[PMID: 18650451]

[5]. Spivak JL: Polycythemia vera: Myths, mechanisms, and management. Blood 100:4272, 2002[PMID: 12393615]

[6]. Chievitz E, Thiede T; Complications and causes of death in polycythemia vera. Acta Med Scand., $1962 ; 172(5): 513$.

[7]. Tefferi A, Thiele J, Orazi A, Kvasnicka HM, Barbui T, Hanson CA et al.; Proposals for revision of the World Health Organization diagnostic criteria for polycythemia vera, essential thrombocythemia, and primary myelofibrosis: From an ad hoc international expert panel. Blood, 2007; 110(4):1092-1097.

[8]. Elliott MA, Tefferi A; Thrombosis and haemorrhage in polycythaemiavera and essential thrombocythaemia. Br J Haematol., 2005; 128(3): 275 